\title{
ESTUDIOS
}

\section{La música gráfica de León Schidlowsky: Deutschland, ein Wintermärchen (1979) como partitura multimedial}

\author{
The Graphic Music of León Schidlowsky: \\ Deutschland, ein Wintermärchen (1979) \\ as a Multimedia Score
}

\author{
por \\ Daniela Fugellie Videla \\ Universidad de las Artes de Berlín, Alemania \\ d.fugellie@udk-berlin.de
}

\begin{abstract}
Este estudio aborda la música gráfica de León Schidlowsky (n. 1931), un género que el compositor cultivara mayoritariamente entre los años 1969 y 1984, inmediatamente tras su emigración desde Israel. Su propósito es presentar un panorama general del desarrollo del lenguaje gráfico del compositor y analizar algunos aspectos específicos de su obra Deutschland, ein Wintermärchen (1979), considerada por la autora como un punto culminante de dicho desarrollo. La investigación destaca la concepción multimedial de la obra, derivada de la técnica del collage, la cual logra sintetizar los diversos aspectos musicales, visuales y performativos, para obtener una visualización simultánea de un arte esencialmente temporal. Asimismo, el estudio profundiza en el contenido social y político de la obra. Postula finalmente que esta concepción heterogénea y multifacética es propia de un compositor transcultural, que transita libremente entre culturas y estéticas diversas.
\end{abstract}

Palabras clave: música contemporánea, multimedialidad, notación musical, notación gráfica, transculturalidad, diáspora, compositores chilenos.

This paper deals with the graphic music of León Schidlowsky (b.1931), a genre cultivated by the composer mostly from 1969 to 1984 after emigrating from Chile to Israel. It presents a general panorama of the development of the graphical language of the composer, and analyzes some specific features of his work Deutschland, ein Wintermärchen (1979), considered by the author of the article as a culminating point of Schidlowsky's creative development. The research underlines the conception of this work as multimedia derived from the collage technique synthesizing the different musical, visual and performative aspects of the work into a simultaneous visualization of what amounts to be an essentially temporal art. Besides, the study explores the social and political contents of the work, to conclude that this heterogeneous and multifarious conception is a natural feature of a transcultural composer, who moves freely among diverse cultures and aesthetics.

Key words: contemporary music, multimedia, musical notation, graphic notation, transculturality, diaspora, Chilean composers. 
"Crecí entre las montañas y el mar. Chile siempre ha estado abierto a las culturas e influencias extranjeras; el país me dio su poesía, sus fuertes colores y su idioma -pero también me hizo ser un rebelde, un extraño, un no-chileno. [...] Mi identidad musical se caracteriza por estar en contra del conservatismo, del folklorismo y de la nostalgia hacia raíces chilenas que nunca existieron realmente. El espíritu de Sudamérica se encuentra en mi música, ese 'algo' especial que resulta del estruendo de montañas enormes, terremotos y mares"1.

\section{REFLEXIONES PRELIMINARES}

La biografía de León Schidlowsky (nacido el 21 de julio de 1931) lo caracteriza como un compositor eminentemente transcultural ${ }^{2}$. Dentro de su triple identificación de chileno crecido en el seno de una familia judía, con una formación fuertemente ligada a la tradición intelectual europea y sobre todo alemana ${ }^{3}$, su obra artística constituye a su vez un testimonio de estas tres esferas culturales. En su música se reúnen la poesía chilena y la europea con elementos musicales y contenidos propios de la cultura judía, temas históricos americanistas, recursos estéticos del expresionismo alemán y las más variadas técnicas de composición internacionales, siempre al servicio de contenidos que apelan al ser humano más allá de las diferencias culturales. Como compositor se destaca desde un comienzo por su afán experimental, que lo llevara, a modo de ejemplo, a componer Nacimiento (1956), la primera obra de música electrónica en Chile $^{4}$, y a probar sin prejuicios estéticos las diversas técnicas composicionales desarrolladas durante el siglo XX. Estas últimas están sintetizadas en su obra v. gr. atonalidad (1952-1954), dodecafonía (1954-1961), procedimientos seriales (1962-1964), experimentaciones con timbres y sonoridades (1964-1967), aleatoriedad (1967-1968), notación gráfica (1969 en adelante), etc. ${ }^{5}$ De esta manera, Schidlowsky resuelve individualmente aquel dilema tan propio del compositor latinoamericano del siglo XX: su capacidad de expresarse a través de técnicas internacionales, en su mayoría procedentes de Europa, sin por ello excluir de

\footnotetext{
${ }^{1}$ Palabras de León Schidlowsky, citadas en Fresis 2001: 35. Esta y todas las siguientes citas originalmente en alemán fueron traducidas por la autora. Esta investigación no habría sido posible sin la colaboración de León Schidlowsky y de su hijo, David Schidlowsky, quienes amablemente respondieron a mis preguntas y me proporcionaron una gran cantidad de materiales inéditos. Reciban ambos mi especial agradecimiento. Los primeros resultados de este trabajo fueron presentados en enero de 2011 en el workshop "Notación gráfica entre abstracción y práctica estética”, realizado por el Instituto Eikones de la Universidad de Basilea, Suiza. Agradezco también a los participantes de este evento por sus valiosas acotaciones y comentarios.

${ }^{2}$ Sobre el concepto de la transculturalidad en la obra de Schidlowsky, véase Daniela Fugellie, "León Schidlowsky, un compositor transcultural", en Schidlowsky 2012.

${ }^{3}$ Esta herencia no es sólo musical, sino que se refleja también, y muy especialmente, en su interés por las artes plásticas y la lírica alemana de principios del siglo XX, al que se agrega su fascinación por artistas tales como Wassily Kandinsky, Paul Klee, George Trakl, Stefan George, Kurt Schwitters, los dadaístas, etc. Ver Grebe 1968: 11.

${ }^{4}$ Sobre esta obra véase Claro 1963: 113-114.

5 Ver el listado de las técnicas gráficas en su propio currículum que figura en el catálogo de la exposición de su música gráfica realizada en Stuttgart, Alemania, en Schidlowsky 1979: imagen 39.
} 
su obra los elementos propios de su identidad o de sus múltiples identidades, todos ellos integrados coherentemente en la obra musical.

Entre los años 1950 y 1952 Schidlowsky fue alumno de composición en Chile del holandés Fré Focke (1910-1989), quien a su vez estudiara entre 1941 y 1944 con Anton Webern en Viena. Ulteriormente Schidlowsky continuó sus estudios musicales en 1952 en Detmold, Alemania. Una gran influencia tendría para él, durante ese período, su participación en 1953 en un curso de verano de Hanns Jelinek (1901-1969), alumno de Schönberg y de Alban Berg, y posteriormente profesor de composición en Viena. Esto le permitió reforzar la herencia que ya había recibido en Chile del alumno holandés de Webern, de modo que llegó a ser una especie de alumno-nieto de la tradición vienesa.

En 1955, Schidlowsky regresa a Chile. Como es sabido, la vida musical chilena se encontraba entonces en el punto culminante de un floreciente desarrollo que había comenzado en las décadas anteriores, impulsado en gran parte por la figura de Domingo Santa Cruz. ${ }^{6} \mathrm{Al}$ interior de la Universidad de Chile, el Instituto de Extensión Musical (IEM) fomentaba la actividad musical a través de sus diversas agrupaciones estables -Orquesta Sinfónica de Chile, Ballet Nacional Chileno, Coro de la Universidad de Chile, además de agrupaciones de música de cámara- como también por medio de los órganos de investigación y educación dependientes de la Facultad de Ciencias y Artes Musicales. La actividad creadora de los compositores chilenos se veía a su vez fomentada por los Premios por Obra y por los Festivales de Música Chilena realizados bienalmente desde 1948. Si bien la enseñanza de la composición musical en el Conservatorio se mostraba reacia a incorporar las técnicas composicionales posteriores al expresionismo, otras iniciativas compensaban dicha carencia al difundir las técnicas y el repertorio de vanguardia al margen de la Universidad. Dentro de los principales gestores de dichas actividades se encontraba el primer maestro de composición de Schidlowsky, Fré Focke, junto a los demás integrantes del ensamble Tonus. Schidlowsky se incorporaría el mismo año de su llegada a dicho ensamble de música contemporánea, conformado por intérpretes y compositores abocados a difundir la música de avanzada de autores europeos, latinoamericanos y de otras regiones del mundo. Incluso llegó a ser su director desde 1957, una vez que Eitler y Focke emigraran de Chile ${ }^{7}$. En poco tiempo Schidlowsky a su vez llegó a formar parte de la institucionalidad musical "oficial", al ocupar cargos tales como el de Secretario de la Asociación Nacional

\footnotetext{
${ }^{6}$ Para mayores informaciones generales sobre esta época, véase "Los años cincuenta en Chile: una retrospectiva” (Autores varios 1997) y González 2006.

7 Como recordara Schidlowsky: "A mi llegada a Chile en 1955, Tonus ya existía por un par de años. Eitler partió de Chile en 1957 y Tonus quedó a mi cargo dos años más. En 1959 ingresamos a la Asociación de Compositores de Chile; la Biblioteca Musical Tonus la doné al Archivo Musical del I.E.M. Tonus dió a conocer en Chile la música atonal y dodecafónica de los maestros: Schoenberg, Berg y Webern, pero además la obra de compositores latinoamericanos, americanos, pero en especial, el énfasis estaba en dar a conocer música chilena que no fuera conformista con la producción tradicionalista del oficialismo musical de esa época. A ese oficialismo musical pertenecían muchos compositores que tal vez ahora se declaran haber utilizado los doce sonidos." Correspondencia del compositor con Silvia Herrera Ortega, citada en Herrera 1985: 183.
} 
de Compositores (1961-1963) y el de Director del Instituto de Extensión Musical $(1962-1966)^{8}$.

Durante la década de los 60, la figura de Schidlowsky era ya reconocida en el ámbito americano. Obras suyas fueron interpretadas en diversos festivales internacionales -a modo de ejemplo, en Washington (1966), Caracas (1966) y Madrid (1967). Además el compositor era invitado a conferencias en distintos países, entre las que se destaca su participación en el Primer Festival Internacional de Música en Mérida (21 al 30 de septiembre de 1968). Junto con dar una conferencia sobre su propia obra, participó en dos mesas redondas de este festival sobre un tema de actualidad, "La música contemporánea y el público". Estas fueron dirigidas por un importante promotor de la música contemporánea en Venezuela, Eduardo Lira Espejo, y también contaron con la participación de Luigi Nono y de Krzysztof Penderecki. En el programa del evento, Schidlowsky era anunciado como "uno de los organizadores fundamentales de la espléndida actividad musical de Chile"9. La obra de Schidlowsky fue reconocida durante estos años también por premios y encargos y llamó la atención de personalidades internacionales del relieve de Hermann Scherchen, en sus visitas a Chile durante los años 60. Scherchen estrenó en 1965 en Suiza la obra orquestal Llaqui (1965) de Schidlowsky junto a la Orquesta de la Radio de Lugano.

En 1969, Schidlowsky emigró a Israel, país donde ocupó el cargo de profesor de composición y teoría musical en la Samuel Rubin Academy of Music de la Universidad de Tel Aviv hasta su jubilación en 2001. Hoy en día el compositor continúa residiendo en dicho país. La relación con sus otras dos 'esferas culturales' tras 1969 ha sido disímil. En los años posteriores a su emigración siguió cultivando lazos con Alemania, país natal de su esposa Susanne, en el que ha realizado estadías de varios meses a lo largo de los años 1979/80, 1992/93, 1998/2000, etc., y en el cual sus obras anotadas en forma tradicional o gráfica han sido objeto de estrenos, exposiciones y de algunas publicaciones en revistas especializadas ${ }^{10}$. El caso de Chile es diferente. Si bien obras suyas se han seguido interpretando, estrenando o incluso grabando en Chile, la figura de Schidlowsky ha estado presente sólo esporádicamente en el medio musical chileno, y ha sido escasamente objeto de la investigación musicológica nacional. Los sucesos posteriores a 1973 influyeron asimismo en un quiebre de las relaciones de Schidlowsky, como las de tantos otros compositores, con su país natal. Algunos de los compositores de su generación reanudarían un contacto permanente con Chile en años posteriores. No obstante, otros, como Schidlowsky, constituyen ese "eslabón perdido" de la música chilena que fueron los prósperos años 50 y 60 .

\footnotetext{
8 Ver mayores informaciones biográficas de esta época en Grebe 1968: 45-47.

9 Programa doble titulado Primera Muestra del Cine Documental Latinoamericano/Primer Festival Internacional de Música, Mérida, 21-30 de septiembre de 1968, sin numeración de página. Los programas del festival de música, el cual fuera realizado paralelamente con un festival de cine latinoamericano, fueron consultados por la autora en el Archivo Luigi Nono en Venecia (abril 2011).

${ }^{10}$ Ver la lista de publicaciones en la bibliografía de este artículo.
} 
De esta manera, Schidlowsky pasa a formar parte del grupo de aquellos compositores que transitan entre países y culturas, artistas que suponen una 'molestia' para la forma tradicional de escribir historia musical, tradicionalmente empeñada en separar a los creadores en naciones, confesiones religiosas, escuelas y estilos bien delimitados. Esta situación ha resultado en que dichos compositores móviles reciban poca atención por parte de la investigación musicológica. Nadie se siente 'responsable' de ocuparse de ellos, al no estar vinculados a un único país o a una sola cultura. En caso de merecer la atención de los investigadores, muchas veces ésta se centra en dar cuenta de los diversos lugares de residencia en la biografía de los artistas, pero no aborda la pregunta central de la influencia de la movilidad en sí en el proceso creativo ${ }^{11}$. En Latinoamérica esta situación no es distinta. La movilidad es un tema central en nuestro mundo globalizado que supone un desafío para la investigación, la cual tendrá que abordar cada vez más los aspectos de la "desterritorialización de la cultura musical chilena y latinoamericana", que abarque como temática a "la esencia e identidad de las culturas musicales latinoamericanas, esta vez dentro de una perspectiva mundial"12. Como la observara Luis Merino:

"Esta perspectiva mundial plantea necesariamente la necesidad de un cambio de enfoque de los musicólogos chilenos y latinoamericanos, a fin de poder abordar simultáneamente el estudio tanto de aquellos rasgos definitorios de la música chilena y latinoamericana, tanto como sus transformaciones dentro de los parámetros de los nuevos entornos creativos a los que se ha incorporado. Además, la globalización de la música chilena y latinoamericana continuará creciendo en el futuro próximo, a medida que Chile rápidamente se integra a las sociedades capitalistas emergentes dentro de la globalización de la economía mundial"13.

Este estudio aborda la música gráfica de León Schidlowsky, un género que el compositor cultivara entre los años 1969 y 1984 y que hasta ahora se desconoce en Chile $^{14}$. Su objetivo es entregar un panorama general del desarrollo del lenguaje gráfico del compositor, sobre la base del análisis de algunos aspectos específicos de su obra Deutschland, ein Wintermärchen (1979), considerada por la autora como un punto culminante de este desarrollo. Se trata de un lenguaje gráfico individual, inclasificable como parte de una sola cultura, estética o de un estilo en particular. No obstante, es posible tematizar la presencia de Latinoamérica dentro de las creaciones gráfico-musicales del compositor. Además será interesante preguntarse por su ausencia, por el vuelco del compositor hacia un nuevo lenguaje musical,

11 Esta temática fue el tema central del último congreso internacional de la Gesellschaft für Musikforschung, realizado entre el 2 y 6 de noviembre de 2010 en Roma y titulado "Movilidad y transformación musical. Música e investigación musical en un contexto internacional". Ver: < http://www. gfm-dhi-rom2010.de > 5.5.2011.

12 Merino 2003: 50.

13 Merino 2003: 50.

$14 \mathrm{Al}$ menos no se cuenta con informaciones sobre interpretaciones de sus obras gráficas en el archivo personal del compositor. Tampoco existen fuentes escritas que testifiquen su interpretación o estudio en Chile. 
único y multidisciplinario, y por la relación de éste con su móvil biografía. De esta manera, el caso de Schidlowsky puede servir para reflexionar sobre la manera en que la musicología deberá abordar la escritura de la historia de generaciones posteriores de compositores, cada vez más inclinados a estudiar y vivir en diversos países y cuya obra reflejará seguramente la transculturalidad de sus biografías.

\section{LA MÚSICA GRÁFICA DE SCHIDLOWSKY (1969-1984)}

En un estudio acerca de este compositor publicado en 1968 en la Revista Musical Chilena, María Ester Grebe realizó una exhaustiva "Síntesis de su trayectoria creativa (1952-1968)"15. El presente artículo abordará la trayectoria inmediatamente siguiente (1969 a 1984), la que corresponde a la fase en la que el compositor trabajara, no exclusiva, pero sí intensamente, en la notación gráfica. Este trabajo coincide con la publicación del catálogo de las obras gráficas del compositor, el cual reúne a su vez varios estudios sobre su obra gráfica ${ }^{16}$.

El corpus gráfico de Schidlowsky abarca, de acuerdo a las informaciones de su archivo personal, 71 obras para diversas formaciones vocales, instrumentales y mixtas, entre ellas algunas obras en varios movimientos, la que constituyen un total de 115 gráficas individuales. La mayoría de ellas fueron compuestas entre 1969 y 1984, un período durante el cual Schidlowsky trabajó en el desarrollo de su particular lenguaje gráfico. Si bien en este período compuso algunas obras orquestales o de música de cámara en notación tradicional, todas sus obras vocales de esta época (a cappella o con acompañamiento, para solistas o para coro) fueron escritas en forma gráfica. A partir de mediados de los años 80, Schidlowsky se vuelca nuevamente a una escritura musical tradicional, y vuelve a utilizar el lenguaje gráfico en casos aislados en los años 1989, 1994 y 199717.

Dichas obras han sido estrenadas y en general interpretadas por diversos ensambles en Alemania (Berlín, Stuttgart, Saarbrücken, Würzburg, Hamburgo) o durante festivales de música contemporánea en Tel Aviv. Algunas obras todavía esperan su estreno. Estas creaciones han despertado también un interés en su aspecto puramente gráfico y han sido mostradas en su calidad de tal en diversas exposiciones en Alemania: Stuttgart (1979), Ludwigshafen (1982), Hamburgo (1980) y Saarbrücken (1996) ${ }^{18}$. Como ya se señalara, hasta el momento no se cuenta con noticias de alguna presentación en Chile de su música anotada de manera gráfica.

15 Grebe 1968.

${ }^{16}$ Este libro recopila la mayor parte de sus obras gráficas, así como un catálogo de ellas y artículos especializados sobre el tema. Se publicó el 2011 en una edición bilingüe (alemán e inglés) en Berlín. Véase Schidlowsky 2011. La edición en español del libro fue editada por RIL Editores en Santiago de Chile. Véase Schidlowsky 2012.

17 Informaciones del archivo personal del compositor, accesibles en el libro ya mencionado. Véase el ya señalado catálogo en Schidlowsky 2011 y Schidlowsky 2012. Ver también su página web: <http://schidlowsky.com/Leon-Schidlowsky.htm> 5.5.2011.

${ }^{18}$ La exposición de Stuttgart 1979 merece una especial consideración al haber sido gestada por el compositor y experto en la notación musical del siglo XX, Erhard Karkoschka, conjuntamente con Karin von Maur, estudiosa de las relaciones entre la música y las artes plásticas. 
Schidlowsky se relaciona en sus creaciones gráficas con una forma de notación musical que se desarrollara a comienzos de los años 50. Entre los representantes de dicha notación puede nombrarse, entre otros, a Earle Brown (1926-2002), Morton Feldman (1926-1987), Roman Haubenstock-Ramati (1919-1994) y Anestis Logothetis (1921-1994). Durante el siglo XX, sobre todo a partir de los años 50, se desarrollaron nuevas técnicas de interpretación para los diversos instrumentos, a la vez que se exploraba con nuevos sistemas de alturas y ritmos. Por su parte, la escritura musical de aquel entonces se desarrolló paralelamente mediante la búsqueda de nuevas formas de notación que se adecuaran mejor a las nuevas exigencias de la interpretación. En el marco de la música aleatoria, se buscaron nuevas maneras de crear formas abiertas. El propósito era otorgar un mayor espacio a la libertad de los intérpretes y aumentar su importancia en el proceso creativo que va desde la primera lectura de una partitura hasta su ejecución en un espacio de concierto. De este modo, la notación gráfica respondía a una tendencia de no pretender dar "instrucciones" a los intérpretes, las cuales debieran resultar en fenómenos musicales indiscutibles. A través de representaciones gráficas de determinadas características, dicha notación busca influir en el músico, al motivarlo a acciones análogas que conduzcan a resultados musicales correspondientes a la noción gráfica original ${ }^{19}$. Así, se amplía el papel tradicional del ejecutante y se le vincula más estrechamente con el proceso de concepción de la obra musical.

Sin embargo, el concepto de notación gráfica agrupa las más variadas formas de notación, las que pueden ir desde un grado muy controlado de aleatoriedad hasta una concepción eminentemente abierta, por lo que el grado de libertad conferido al intérprete varía de obra en obra. Erhard Karkoschka, autor de un pionero estudio sobre la notación de la nueva música ${ }^{20}$, habla de cinco grados, de acuerdo a la cercanía o lejanía con respecto a la notación musical tradicional. Estos oscilan desde (1) obras que constan de elementos gráficos, pero cuyos signos están bien definidos y dejan poca libertad a la ejecución, pasando por (2) obras en las que los signos y símbolos están más o menos definidos, y que dirigen la lectura por medio de ordenaciones que se asemejan a las líneas del pentagrama, y (3) gráficas en las que no puede identificarse ni un principio ni un final, ni tampoco la dirección de la lectura es clara, pero que pueden ser leídas a través de procesos asociativos. En el extremo opuesto se encuentran (4) obras que no constan ya de signos 'traducibles' en música, los cuales están ahí sólo para influenciar de manera libremente asociativa al intérprete, y (5) finalmente las notaciones gráficas de otras obras que no han sido creadas para ser traducidas en fenómenos musicales, pero cuya concepción se ve influenciada por una determinada estética musical, sin poder ser clasificadas como partituras en el sentido funcional del término ${ }^{21}$. Al ganar así la notación en elementos gráficos, el aspecto temporal de la obra musical se ve traducido en una representación espacial.

${ }^{19}$ Para informaciones generales sobre la notación gráfica, veáse Möller 1997: 354 y Karkoschka 1966: 2.

${ }^{20}$ Este estudio se encuentra en la bibliografía como Karkoschka 1966.

${ }^{21}$ Esta clasificación se encuentra en Karkoschka 1980: 137. 
En el contexto de este desarrollo, el caso de Schidlowsky es sin duda particular, por haberse dedicado a lo largo de 15 años tan intensamente a este género. Dicha búsqueda ha culminado en una novedosa concepción de obras en muchos movimientos y de gran formación vocal e instrumental, las cuales lo colocan entre los exponentes más interesantes de dicho género. Como destacara Karkoschka refiriéndose a este compositor: "Un artista que hace suyo un tema que significa una atrocidad para los conservadores, mientras que para los modernistas ya ha dejado de ser la última moda, será desaprobado por ambos. Si él aún así persiste en ese tema a lo largo de los años, entonces merece nuestra especial consideración" 22.

\subsection{Inicios del lenguaje gráfico}

La decisión de experimentar con formas de notación no tradicionales obedece en el caso de León Schidlowsky, en sus propias palabras, a una "necesidad", ya que las nuevas técnicas composicionales utilizadas por él requerían de una nueva forma de notación. Si bien dicha necesidad ya se manifestaba en obras anteriores a 1969, fue en ese año cuando el compositor comenzó consecuentemente "a usar una totalidad gráfica como una representación de una realidad musical”23. No obstante, el desarrollo anterior a 1969 merece ser brevemente considerado.

En su estudio de 1968, María Ester Grebe observaba un desarrollo del lenguaje del compositor hacia técnicas aleatorias. El período entre 1964 y 1968 fue designado por ella justamente como "período aleatorio", caracterizado por un cambio radical en el lenguaje musical, que utilizaba procedimientos que lo liberaran de parámetros rígidos ${ }^{24}$. En las obras de 1964 a 1966, dicha situación se refleja sobre todo en la aparición de alturas indeterminadas en algunas secciones de obras escritas mayormente en una notación tradicional, las que utilizan como recursos musicales los clusters en totalidades cromáticas, cuartos de tono, diferentes opciones de vibrato y la estratificación de la estructura en bloques colorísticos. Entre las obras de este período pueden mencionarse Invocación (1964), Llaqui (1965) y Nueva York (1965) 25 .

Las obras de los años 1967/68 -definidas por el compositor como el período del "azar"26 - se caracterizan por una emancipación de estos elementos. La libertad alcanzada desemboca en una ruptura con el sistema temperado, así como en una emancipación de los principios de duración, y en nuevos procedimientos gráficos que pasan a formar parte del lenguaje musical. En Imprecaciones (1967) para coro mixto Schidlowsky hace "su primer ensayo de notación gráfica", al dotar a cada parte vocal de una trayectoria lineal, mientras que las intensidades se expresan en signos convencionales y la velocidad es medida en segundos ${ }^{27}$. Un ensayo de notación gráfica rítmica se observa en Seis hexáforos para Juan Manuel (1968), cuyos

\footnotetext{
22 Citado de su artículo en el catálogo de la exposición en Stuttgart. Véase Karkoschka 1979: 12

23 Schidlowsky 1979: 1, texto inédito.

24 Grebe 1968: 29.

25 Grebe 1968: 32-33.

${ }^{26}$ Dentro de su ya mencionado currículum gráfico, en Schidlowsky 1979: imagen 39.

27 Grebe 1968: 38-39.
} 
valores rítmicos individuales no son absolutos, sino que deben leerse en el contexto de las relaciones polirrítmicas establecidas entre los diferentes intérpretes ${ }^{28}$.

La "crisis de las alturas determinadas", el consiguiente "debilitamiento de la interválica" y el "relajamiento de las duraciones determinadas" eran entendidos por el compositor en 1968 como una "liberación"29. Importante es destacar que dicha libertad no pretendía desembocar en un mero "anything goes" (todo vale). Como compensación, otros parámetros pasan a ganar importancia en la creación musical, como son el timbre y los aspectos dramáticos y semánticos. Ya en aquel entonces se observaba una "exacerbación de los efectos dramático-expresivos en voces e instrumentos como una creciente importancia del mensaje social, político, ético o religioso de los textos literarios" ${ }^{30}$. El uso de la aleatoriedad como técnica compositiva no obedece entonces, en el caso de Schidlowsky, a una posición intrascendente o irónica. La aleatoriedad no significa para él la abolición del concepto tradicional de obra de arte. Por el contrario, el artista sigue creyendo en su capacidad de transmitir un mensaje y de dar testimonio de su compromiso social.

El predominio de la representación gráfica a partir de 1969 obedece pues al afán de sintetizar algunas técnicas composicionales propias de la segunda mitad del siglo XX (aleatoriedad, notación proporcional, formas abiertas) exploradas por el autor durante años anteriores, las que le otorgan a los intérpretes la posibilidad de participar imaginativamente en el proceso creativo. A continuación se demostrará cómo el compositor explotó, a través de la notación gráfica, la posibilidad de trabajar flexiblemente en una síntesis de elementos diversos. Esto desembocó en una concepción cada vez más compleja, un "arte global (Gesamtkunstwerk), donde la acción (teatro), imagen (plástica), el sonido (música), texto (literatura) son intercomunicables" 31 .

\subsection{De la introspección al teatro musical}

Las obras gráficas de Schidlowsky se caracterizan por una marcada individualidad. Cada obra, por sí misma, representa un universo gráfico particular, el cual encuentra su correspondencia en una sonoridad específica ${ }^{32}$. Sin embargo, es posible describir a grandes rasgos un desarrollo en su lenguaje, a pesar de no ser este completamente lineal. Durante los años 1969-1971 se aprecia el predominio de obras instrumentales para diversas formaciones. Muchas de ellas se caracterizan por una marcada abstracción. El compositor trabaja aquí con elementos básicos (puntos, líneas rectas, diagonales y curvas) y construye con ellos formas geométricas elementales (círculos, triángulos, cuadrados) repartidos en el espacio, los

28 Grebe 1968: 40. Ver ejemplos de la notación de las obras mencionadas en este mismo artículo.

29 Schidlowsky, citado en Grebe 1968: 31.

30 Grebe 1968: 32.

31 Schidlowsky 1979: 1, texto inédito. Mayores aclaraciones sobre el término Gesamtkunstwerk y sus implicaciones en la obra de Schidlowsky se encuentran en el punto 3.1. de este artículo.

32 "Cada obra debe poseer su propio orden, debe tener su propia singularidad. Cada obra contiene un mundo propio, plástico, teatral, poético, pero fundamentalmente musical”. Schidlowsky 1979: 2, texto inédito. 
cuales pocas veces persiguen fines figurativos. Su obra Música para piano y vientos, perteneciente a su Tetrálogo (1972), estrenada en Tel Aviv, constituye una muestra de esta estética eminentemente abstracta (ver imagen 1).

Según observara la historiadora del arte Karin von Maur, dicha utilización de signos elementales, predominantemente geométricos, no puede dejar de recordar a Wassily Kandinsky en su camino a la abstracción ${ }^{33}$. Los escritos del pintor se destacan por sus frecuentes analogías musicales. Sin ir más lejos, su interés por la abstracción propia de la música es uno de los aspectos que lo impulsaron en su camino a la abstracción pictórica. Los signos de estas primeras obras gráficas de Schidlowsky se asemejan a la estética del Kandinsky de Punkt und Linie zu Fläche (1926) (Punto y línea sobre el plano), un libro que el compositor leyera años antes de desarrollar su lenguaje gráfico ${ }^{34}$. En dicho escrito, Kandinsky propone una sistematización de sus teorías sobre la constitución de las formas en base a elementos básicos, punto y línea, y su distribución en el plano. De acuerdo a las ideas de su escrito Über das Geistige in der Kunst (1911) (Sobre lo espiritual en el arte), el artista propuso una teoría de la abstracción dotada de contenido y de espiritualidad. Siguiendo a sus alusiones musicales, el pintor propuso una "traducción" de algunos compases de la Quinta Sinfonía de Beethoven en figuras elementales (ver imagen 2).

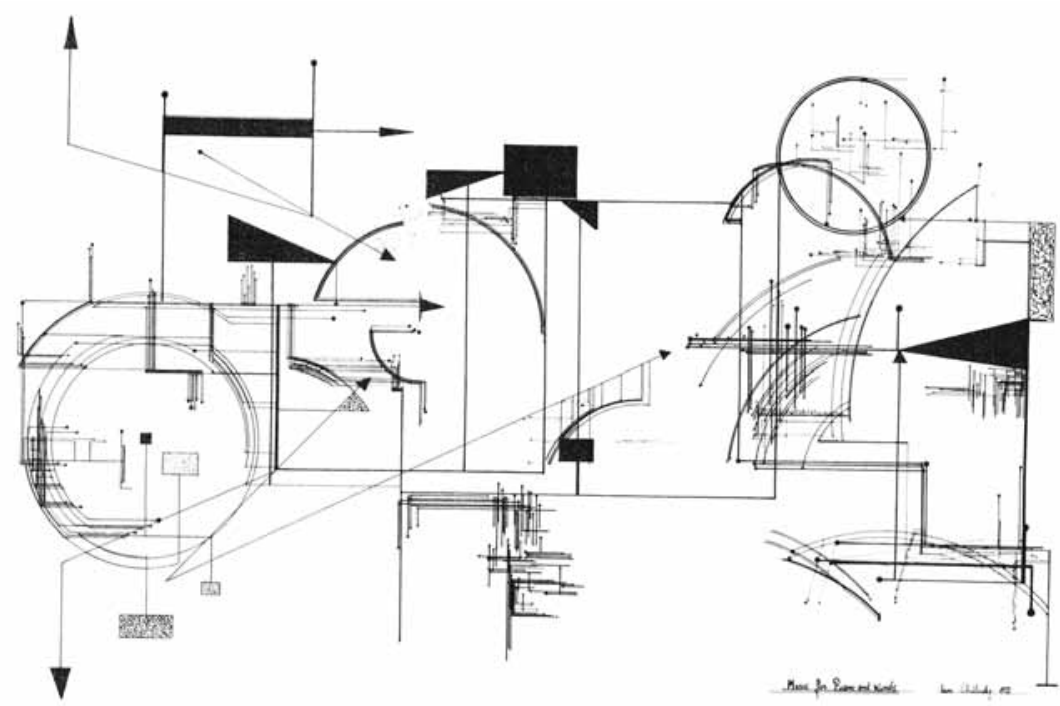

Imagen 1. Música para piano y vientos, 1972. León Schidlowsky, archivo personal.

33 Von Maur 1979: 9.

${ }^{34}$ A la influencia de este libro se refirió el compositor en una entrevista con la autora, en la que indicó que la "traducción" de elementos musicales en figuras geométricas básicas, tal como en el citado ejemplo de Beethoven, le causó una gran impresión aún estando en Chile, en momentos en que buscaba nuevos caminos en su creación. Entrevista con León Schidlowsky, Berlín, 7 de septiembre de 2011. 

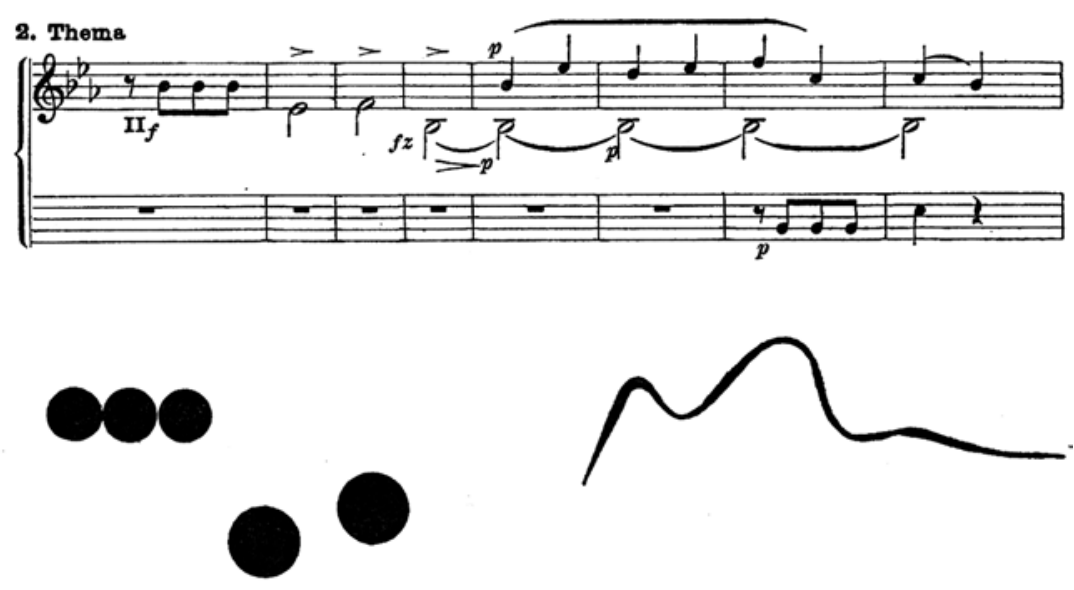

Imagen 2. Kandinsky 1955 [1926]:46. VG Bild-Kunst, Bonn 2011.

Tal como en el ejemplo de Kandinsky, la notación de Schidlowsky, a primera vista hermética, debe leerse a su vez como un sistema de relaciones. La ubicación de los signos en el espacio alude a las alturas sonoras mientras que la densidad de la textura y el tamaño de los objetos se relacionan con la dinámica. Figuras que insinúan flechas pueden dirigir la lectura o los movimientos de los intérpretes, mientras que otras formas más complejas pueden leerse asociativamente. A modo de ejemplo, las diferentes figuras encerradas en figuras rectangulares sugieren diversos tipos de textura sonora. Dichas obras son primariamente abstractas, ya que no buscan representar miméticamente objetos de la realidad. Sin embargo, esto no quiere decir que sean totalmente herméticas. En palabras del autor: "Aun en las obras que aparentemente son estrictamente abstractas existe siempre un diálogo, un drama, un lirismo representado por las diferentes figuras gráficas" ${ }^{35}$.

Paulatinamente el aspecto teatral o dramático cobra mayor importancia en el contexto de las creaciones gráfico-musicales de Schidlowsky. Desde 1972 cada vez son menos las obras instrumentales y más las que incluyen cantantes o recitadores con acompañamiento instrumental o a cappella. Los textos utilizados provienen de fuentes culturales y estéticas diversas. El compositor recurre, entre otros, a poemas de Kurt Schwitters, Hugo Ball y Walter Mehring, a la lírica de Edgar Allan Poe, Gertrude Stein, Pablo Neruda o Paul Eluard, a textos hebreos antiguos, a citas bíblicas, etc. Sobre todo en las obras que involucran cantantes y recitadores, la notación deja de ser una instrucción dirigida solamente al aspecto sonoro de la obra y pasa a involucrarse con otro parámetro fundamental: el movimiento. Las

35 Schidlowsky 1979: 2, texto inédito. 
figuras distribuidas en el papel se convierten en una cartografía mediante la cual los intérpretes puedan moverse a lo largo de la representación. La partitura pasa a ser así una representación gráfica del escenario en el cual los cantantes o recitadores tendrán que desenvolverse, acompañados por variadas formaciones instrumentales, las cuales muchas veces son ad libitum. Por ejemplo, DADAYAmasONG (1975), para cantante y ensamble instrumental, se compone de 21 secciones numeradas. Durante la interpretación, la cantante debe moverse en el escenario siguiendo los números progresivamente, los cuales se encuentran "desordenados" en el espacio. La heterogénea tipología de letras del canto, típica de los dadaístas, alude a diversas dinámicas y alturas. Por su parte, los instrumentistas cuentan con una notación mixta, compuesta tanto de neumas tradicionales, incluso parcialmente ordenados en pentagramas, como de figuras geométricas, que dan el pie para crear asociativamente diversas texturas sonoras. Cada movimiento de la cantante significará el comienzo de un nuevo número, y con él, la creación de un nuevo carácter musical $^{36}$ (ver imagen 3 ).

De esta manera, el aspecto de la performatividad se incorpora como parte de las 'informaciones' suministradas por la notación musical, lo que realza su rol en el contexto global de la interpretación. La superficie del papel puede entenderse como una representación de la superficie móvil y temporal de la obra musical. En esta concepción de la superficie como un organismo abierto, en el cual

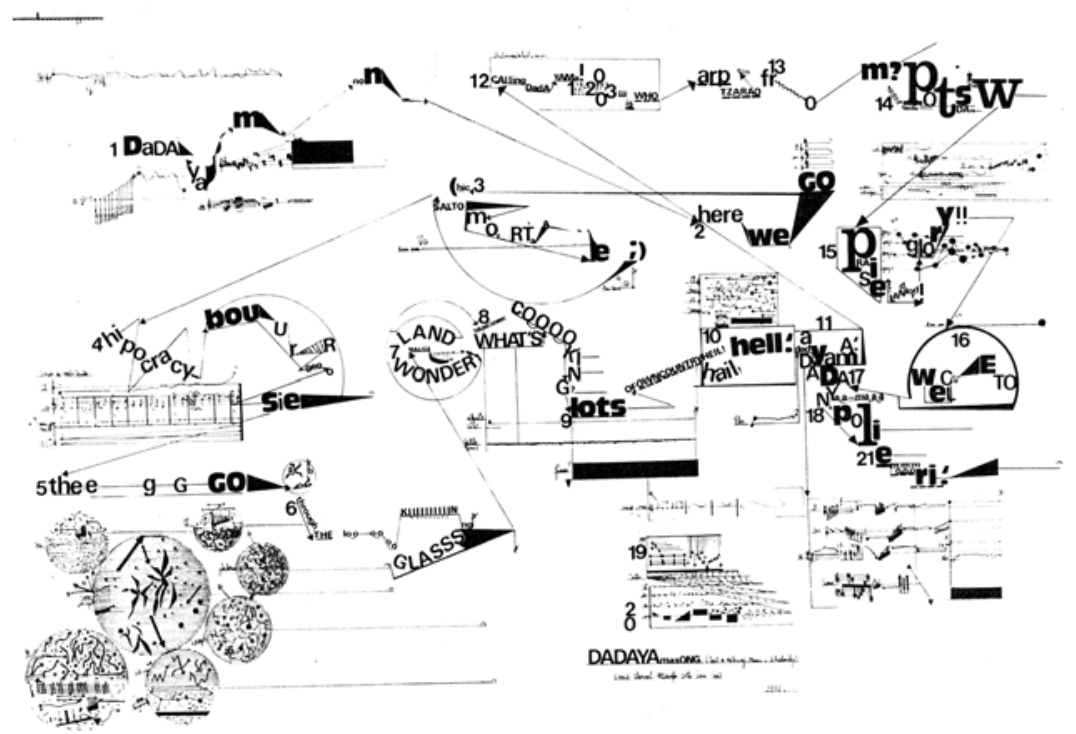

Imagen 3. DADAYAmasONG, 1975. León Schidlowsky, archivo personal.

36 Ver un análisis de la notación de esta obra en Karkoschka 1980. Dicho texto se encuentra a su vez, en su traducción al español por la autora de este artículo, en Schidlowsky 2012. 
conviven diversos elementos, sonoros y performativos, se encuentra nuevamente una similitud con la estética de Kandinsky, en su concepción del plano como un "organismo viviente":

"El artista 'fecunda' ese organismo y sabe con qué obediencia y 'alegría' el plano asimila los elementos correctos en el orden correcto. Este organismo primitivo, pero vivo, se transforma a través de un tratamiento adecuado en un nuevo organismo viviente, que ya no es primitivo, sino que manifiesta todas las características de un organismo desarrollado"37.

A partir de 1976, el compositor alcanza lo que podría llamarse una última etapa de su notación gráfica. Junto con seguir componiendo obras predominantemente con texto, se destaca la creación de obras extensas, en varios movimientos, concebidas para grandes formaciones (coros mixtos, diversos solistas vocales, órgano, diversos instrumentos de percusión). Cabe mencionar su Misa sine nomine (1976/77) dedicada a la memoria de Víctor Jara, en once gráficas para diferentes formaciones; Deutschland, ein Wintermärchen (1979), obra que será comentada a continuación; Der schwarze Gott (1980) para coro femenino, flauta, arpa y órgano, en siete partes, y su obra tardía Greise sind die Sterne geworden. Eine moderne Passion (1997) para solistas, coro, piano, celesta, órgano, percusionistas y dos coros mixtos, en once secciones.

En estas últimas obras Schidlowsky llega a una concepción única, la cual puede definirse como una forma experimental de teatro musical. En comparación con la abstracción de las primeras obras gráficas, estas obras en varios movimientos son eminentemente dramáticas. Buscan crear atmósferas diversas y transportar mensajes que apelan directamente al espectador, y que combinan el aspecto sonoro con el aspecto visual y performativo. Desde 1979 el color pasa también a formar parte de algunas de las obras. A través de la sumatoria de elementos complementarios a los musicales dentro de la notación, la partitura gráfica y el escenario se han vuelto paulatinamente uno solo. En el análisis de su Wintermärchen se tratarán estos aspectos en detalle.

\section{3. "Música gráfica” y su lectura}

En este estudio se ha decidido utilizar el término "música gráfica" para las obras de Schidlowsky y no el utilizado comúnmente de "notación gráfica”. Este es el término elegido por el compositor, quien sostiene haberlo tomado de un importante exponente del género, Roman Haubenstock-Ramati. ${ }^{38}$ Dicha designación puede parecer contradictoria, al reunir a dos medios aparentemente irreconciliables entre sí, ya que para que la música se vuelva "gráfica" o, expresado de manera inversa, para que la gráfica se convierta en "música", alguno de los dos medios tendría que ceder en favor del otro. El término es favorecido por Schidlowsky por

\footnotetext{
37 Kandinsky 1955: 131.

38 Entrevista con León Schidlowsky, Berlín, 7 de septiembre de 2011.
} 
representar justamente una forma de síntesis, en la que la gráfica contiene no sólo el fenómeno sonoro, sino que también el espacio en el cual los intérpretes se mueven, los textos interpretados, y en fin los diversos elementos de la concepción, los cuales interactúan entre sí al interior de la obra. Debido a su multimedialidad, el compositor favorece la proyección de las gráficas durante la interpretación de sus obras, de modo de ampliar la ejecución a este aspecto visual tanto para los intérpretes como para los auditores ${ }^{39}$.

Por último, el lector tal vez se preguntará por asuntos prácticos, luego de haber visto los primeros ejemplos gráficos, en cuanto a la legibilidad de estas partituras. La notación gráfica no llegó a sistematizarse a lo largo del siglo XX. Cada compositor ha creado su propio sistema de relaciones, al utilizar signos y símbolos elegidos por cada uno, a los que dota de significados de acuerdo a una lógica interna. Las partituras gráficas de Schidlowsky son entendidas por él como "una escritura global donde se informa al intérprete del material que se pretende usar y sus posibilidades" 40 . Al contrario del caso de, por ejemplo, Logothetis, quien catalogó sus signos gráficos y sus funciones para proveer al intérprete de explicaciones sistematizadas, las obras de Schidlowsky no suelen acompañarse de comentarios que ayuden a entender los diversos signos utilizados. Mientras Karkoschka, en su estudio sobre DADAYAmasONG, destacaba que muchos de los signos y neumas se entienden en la lógica del contexto (alturas por la ubicación en el espacio, dinámica por el tamaño de las figuras en relación entre sí, etc.) ${ }^{41}$, en algunas obras el ejecutante tendrá dudas sobre la lectura de signos que se prestan a diferentes interpretaciones. Por lo tanto, una explicación sería útil para facilitar su comprensión. Naturalmente, el primer requisito para el intérprete será no tener miedo a improvisar asociativamente y buscar creativamente posibilidades que lo lleven a obtener resultados coherentes entre sí.

Pese a que una gran parte de la interpretación se deberá al aporte creativo del ejecutante, cabe destacar que muchas de las representaciones de obras gráficas de Schidlowsky han sido el resultado de un trabajo conjunto entre el compositor y un director musical. Durante este trabajo se ha discutido sobre la interpretación de las gráficas personalmente, lo que le ha dado al compositor la ocasión de explicar ampliamente su concepción total y en cuanto a movimientos, iluminación, etc. Este punto es destacado por Ingo Schulz, director musical de la Iglesia de Ölberg en Kreuzberg, Berlín, quien a lo largo de los años ha interpretado y grabado una gran cantidad de obras de Schidlowsky, entre ellas sus obras de gran formato, junto a músicos profesionales y aficionados. No obstante la gran libertad propia de esta notación, el compositor tiene ideas claras con respecto a los diversos aspectos (sonoros y performativos) de la interpretación, de modo que el ensayo de las obras ha significado un proceso creativo en conjunto entre su autor, el director musical y los intérpretes ${ }^{42}$.

\footnotetext{
39 Así lo señaló el compositor en la mencionada entrevista con la autora, 7 de septiembre de 2011.

${ }^{40}$ Schidlowsky 1979: 1, texto inédito. El compositor también utiliza la variante de "gráfica musical".

41 Karkoschka 1980: 137-147.

42 Entrevista de la autora con Ingo Schulz, Berlín, 10 de marzo de 2011.
} 
En el archivo personal del compositor se cuenta además con algunos textos que explican en detalle la concepción de algunas de las obras, los que complementan las informaciones anotadas gráficamente. El mismo compositor parece estar de acuerdo con la utilidad de este material cuando dice: "esta concepción ha obtenido resultados auditivos inesperados, que hubieran sido imposibles de obtener con una escritura tradicional. Esto me ha llevado a la conclusión de que es posible de obtener el ideal dando al ejecutor una información adecuada para su realización" 43 . La elaboración de una edición comentada de las obras gráficas de Schidlowsky, que aporte con la información adicional adecuada para facilitar su interpretación, supone una interesante tarea que espera su realización.

\section{Deutschland, ein Wintermärchen (1979)}

"El grafismo es una forma cerrada de un organismo abierto" 44

Esta obra en siete movimientos está concebida para coro mixto, un recitador, cantante solista, piano y un ensamble de percusión. Su título proviene del libro homónimo de Heinrich Heine (1797-1856), un poeta con el cual Schidlowsky tiene bastante en común. Como Schidlowsky, Heine era un intelectual de origen judío, y como él estuvo comprometido con los temas y problemas de la sociedad de su época. A su vez, Heine fue un artista que emigró de su país natal, Alemania, en su caso a Francia. Su Deutschland, ein Wintermärchen (1844) (Alemania, un cuento de invierno) constituye una crítica a la sociedad alemana desde la perspectiva de un emigrante, quien viaja a su país natal por primera vez en 1843, tras varios años de ausencia. Schidlowsky escribió su Wintermärchen en Hamburgo - una ciudad en la que viviera a su vez Heine- en 1979, durante una permanencia en Alemania que se extendería hasta 1980. Como el escritor del siglo XIX, Schidlowsky volvía a Alemania para realizar su primera estadía prolongada en este país en el que estudiara en la década de los 50 . A su vez, su obra constituye una crítica a la sociedad alemana desde el punto de vista de las impresiones de un viajero. En su caso él cuestiona la sociedad de consumo, los dogmatismos rígidos que encontraba en dicha sociedad, y alude también en su último movimiento al antisemitismo. La estructura de la obra es la siguiente (ver tabla 1).

La concepción musical de la obra es prácticamente inseparable de su calidad visual. Dos de los parámetros considerados tradicionalmente en un análisis musical, ritmo y alturas, no se encuentran definidos, sino que más bien son sugeridos por la notación gráfica. Por lo tanto, un comentario sobre la estructura y materiales musicales de Deutschland, ein Wintermärchen será, por decirlo así, equivalente a un comentario sobre la notación propiamente tal y las posibilidades que proporciona a los intérpretes. Junto con el análisis musical en sí, deberá tenerse en cuenta que esta notación entrega información adicional, correspondiente a instrucciones de movimiento, iluminación y otras, según se tratará en el punto 3.1.

\footnotetext{
43 Schidlowsky 1979: 2, texto inédito, comentarios adicionales con fecha de 2010.

44 Schidlowsky 1979: 1, texto inédito.
} 
TABLA N ${ }^{\circ} 1$

DEUTSCHLAND, EIN WINTERMÄRCHEN, ESTRUCTURA

\begin{tabular}{|lll|}
\hline Movimiento & \multicolumn{1}{c|}{ Traducción } & \multicolumn{1}{c|}{ Formación } \\
\hline 1. Du sollst nicht & No harás & recitador, cantante, coro, piano, percusión \\
2. Du darfst nicht & No debes & cantante, coro, piano, percusión \\
3. Du kannst nicht & No puedes & cantante, coro, percusión \\
4. Zur Sache & Manos a la obra & recitador, cantante, coro \\
5. Weltanschauung & Cosmovisión & cantante, piano, percusión \\
6. Wer ist schuldig & Quién tiene la culpa & recitador, cantante, coro, piano, percusión \\
7. Der Traum vom Vierten Reich & El sueño del Cuarto Reich & recitador, coro, percusión \\
\hline
\end{tabular}

En general, puede hacerse una distinción entre la notación destinada a las partes vocales e instrumentales. Los cantantes -coro y solistas- son instruidos por neumas muy diferenciados, que exigen diversas técnicas y efectos vocales. Los neumas más importantes son los siguientes ${ }^{45}$ (ver imagen 4 ).

La dinámica del canto está determinada por el tamaño de los signos (cuanto más grande, más fuerte), mientras que las alturas deben interpretarse proporcionalmente. Se entiende que en cada gráfica el extremo superior corresponde al registro agudo y el inferior al registro grave, por lo que las alturas se desenvuelven entre estos dos extremos. Si bien la notación a primera vista pudiera parecer muy libre, se puede observar cómo gran parte de los efectos esperados están claramente delimitados. Tomando como guía las informaciones proporcionadas, los cantantes podrán crear dinámicas y efectos variados que van desde el murmullo hasta el grito, utilizando a su vez una amplia gama de alturas ${ }^{46}$. La existencia de neumas que designan estructuras polifónicas contribuye a variar la densidad de la parte vocal, la que oscila desde movimientos en que predominan los fonemas aislados (a modo de ejemplo en el primer movimiento) a otros caracterizados por la polifonía vocal (a modo de ejemplo en el cuarto y sexto movimiento). La parte solista (declamador y cantante) está en cambio escrita de manera variada. Su notación consta de partes definidas por neumas diferenciados y de otras partes libres, en las que el texto no se acompaña de neumas musicales. En estas últimas se espera que los intérpretes reflejen el dramatismo del contenido del texto para lo que libremente deben valerse de diferentes efectos.

45 Véase el artículo de Ingo Schulz en Schidlowsky 2011: 43-73 y su traducción al español por la autora de este artículo en Schidlowsky 2012: 55-85.

46 Cabe destacar que el significado de los neumas vocales no puede deducirse simplemente del contexto. El significado de rombos, cruces y rectángulos como diversas maneras de cantar exige una explicación adicional, la cual deberá ser considerada en futuros proyectos de edición de las obras gráficas de Schidlowsky. 


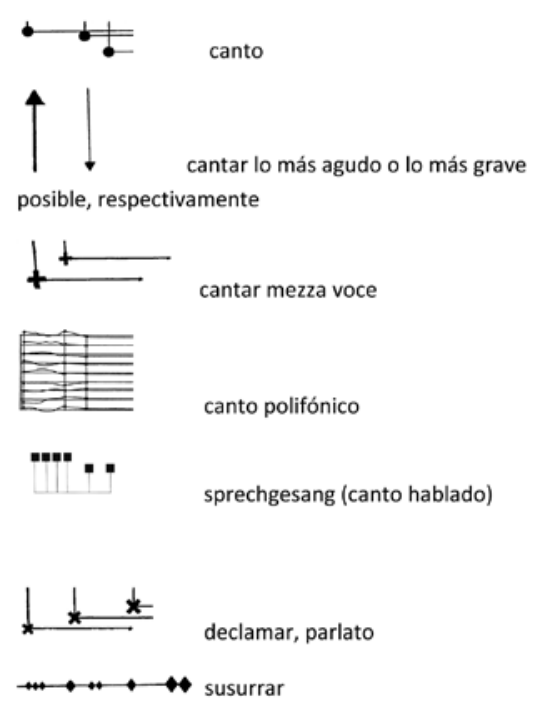

Imagen 4. Neumas vocales principales y su significado.

La parte instrumental de la obra posee una notación mixta. Parcialmente, ésta consta de signos musicales provenientes de la notación tradicional, tales como llaves, pentagramas o figuras rítmicas tradicionales. En la mayoría de los casos, los instrumentistas encontrarán sólo alusiones abstractas, por lo que se espera de ellos que transporten asociativamente los colores y texturas visuales de las diversas gráficas a timbres y figuras musicales. De esta manera, los instrumentos elegidos, piano y percusión, determinan el timbre instrumental de la obra y crean una red sonora sobre la cual se desenvuelve el canto. A la parte de la percusión se le asigna una gran libertad y puede utilizar un amplio instrumentario para crear atmósferas diversas. Es importante destacar que aunque las figuras no señalan alturas absolutas, la regla "implícita" consiste en situarse en el marco de un atonalismo libre y expresivo, aboliendo relaciones tonales o funciones armónicas más tradicionales ${ }^{47}$.

En el primer movimiento, Du sollst nicht, pueden observarse los distintos tipos de notación. Las letras y fonemas aislados repartidos en el espacio están destinadas al coro, mientras que las frases provenientes de recortes de revistas al centro de la gráfica deben ser declamados libremente por la cantante y el recitador. Del coro se espera, así, la emisión individual de sonidos, en un registro agudo, medio y grave, como se desprende de su distribución en el espacio. Las letras aisladas se combinan con figuras geométricas repartidas a su vez en la gráfica (cuadrados, cruces, círculos, rombos), lo que indica que los cantantes deberán utilizar los diversos

${ }^{47}$ En la entrevista con la autora ya señalada (Berlín, 7 de septiembre de 2011) el compositor destacó la utilización de un lenguaje atonal. Esta regla "implícita" constituye para Schidlowsky una consecuencia obvia del desarrollo de la estética de la música a lo largo del siglo XX y a partir de la dodecafonía. 
recursos vocales ya señalados (cantar, declamar, susurrar, etc.). Los solistas, en cambio, deberán basarse en los textos de los recortes de revistas, los cuales no se acompañan de símbolos musicales. Esto les confiere una libertad para improvisar mucho mayor que a los cantantes del coro. Los neumas musicales destinados a los instrumentistas se encuentran en su mayoría enmarcados en el rectángulo inferior izquierdo. El papel de pauta en el que están inmersos, y la llave de Fa que los precede, sugiere un registro grave, correspondiente a su ubicación en el extremo inferior. Junto con figuras geométricas, que podrían ser interpretadas como tonos independientes, se encuentran líneas verticales y horizontales caracterizadas por distintas texturas y colores, las que claramente están pensadas para su transposición asociativa en ideas musicales. Al no existir otras indicaciones, el resultado sonoro de la parte instrumental dependerá de la fantasía de los intérpretes para improvisar y variará en cada ejecución (ver imagen 5).

Es interesante destacar que en este primer movimiento se encuentra a su vez una cita de la notación tradicional, reflejada en tres líneas melódicas escritas sobre pentagramas y ubicadas en torno a la letra "M" dentro del rectángulo destinado a la parte instrumental. La melodía inferior, compuesta de 12 tonos, puede relacionarse con una serie dodecafónica, cuya segunda mitad constituye una retrogradación invertida de la primera parte. Diez de sus doce tonos corresponden a esta observación. De esta manera, el autor alude indirectamente a la técnica que constituyó, para él como para muchos otros compositores del siglo XX, el punto de partida en el camino hacia la aleatoriedad. Como ya se señaló, y pese a su aparente

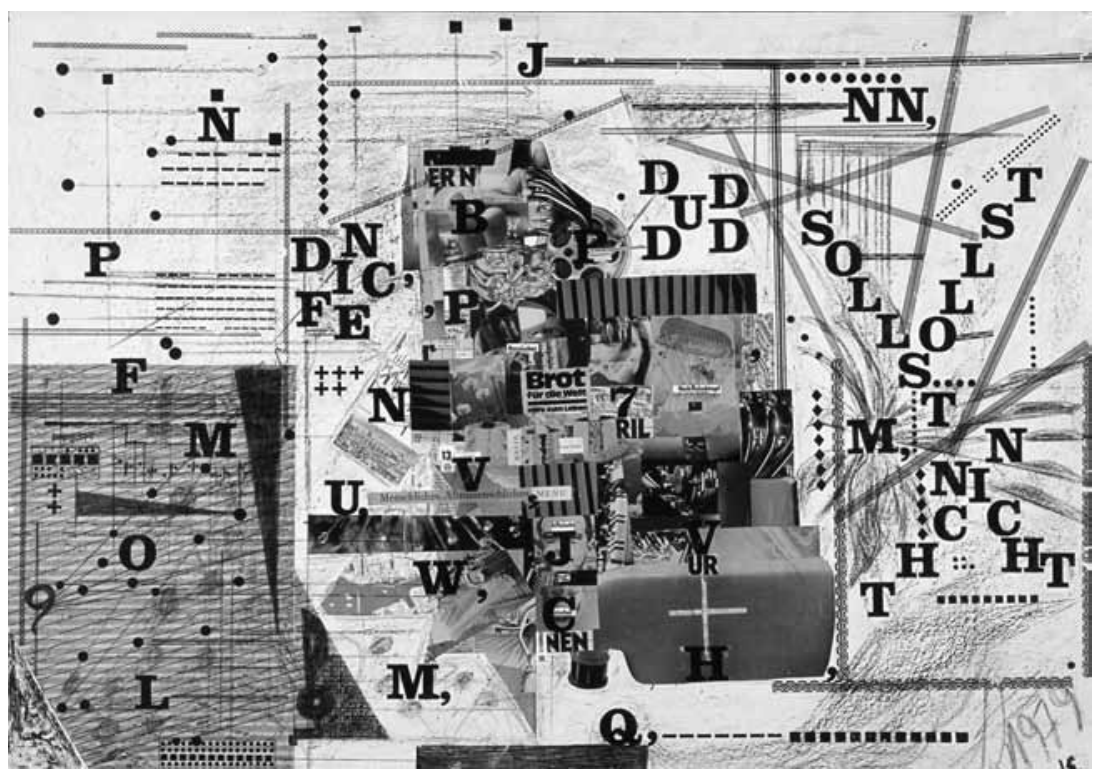

Imagen 5. Deutschland, ein Wintermärchen, primer movimiento: Du sollst nicht. León Schidlowsky, archivo personal. 
libertad, la aleatoriedad mantiene un alto grado de constructividad, dentro de la cual el azar aparece de manera controlada y organizada. Si se lee la línea como si estuviera precedida por una llave de sol, la serie sería la siguiente (ver imagen 6).
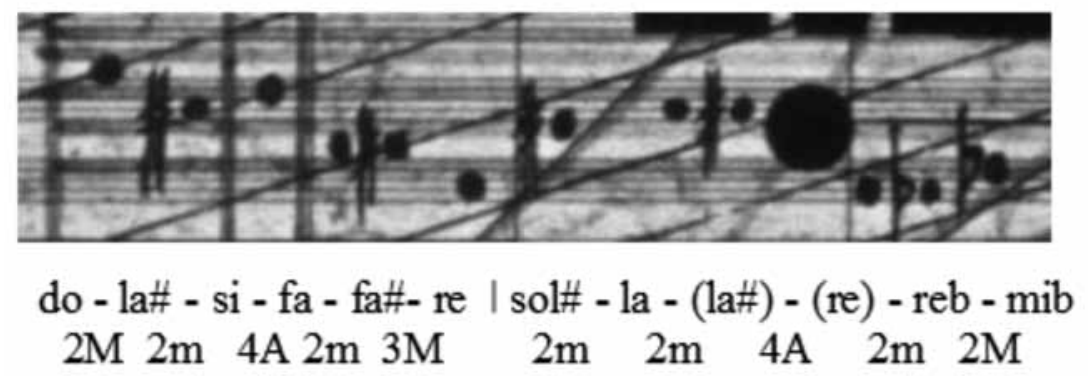

Imagen 6. Deutschland, ein Wintermärchen, primer movimiento: fragmento.

Por otra parte, el orden en el que se interpretarán las diversas estructuras es libre, salvo que exista una numeración, como se verá en el quinto movimiento. El director musical debe decidir previamente el orden en que se sucederán las estructuras musicales. Por razones de espacio, no se analizan aquí las siete gráficas y la dramaturgia de la obra en detalle, sino que se comentarán los aspectos centrales de la concepción general. Para una visión de las siete gráficas que constituyen la obra, se recomienda consultar el catálogo del autor ${ }^{48}$.

\subsection{Gesamtkunstwerk, collage y multimedialidad}

Gráficamente cada movimiento de la obra constituye un collage en el cual el compositor combina libremente dibujos, neumas musicales, letras, fonemas, recortes de revista y formas abstractas. Los textos de los diversos movimientos, algunos compuestos solamente de frases cortas, junto a otros más extensos, son de autoría del compositor. Por primera vez Schidlowsky utiliza el color como parte de su concepción, el cual acentúa el carácter dramático de los distintos movimientos. Como ya fuera señalado en ejemplos anteriores, la gráfica también constituye en este caso una representación del escenario, dentro del cual los sonidos, el movimiento y los diversos textos crean una obra de arte multimedial.

Para entender esta concepción de collage en su significado profundo, cabe diferenciar las diversas categorías encerradas en su interior y en sus funciones. En primer término se pueden distinguir dos categorías fundamentales al interior de la notación gráfica: signos (o neumas) y símbolos ${ }^{49}$. Los signos pueden ser entendidos funcionalmente como objetos enmarcados en un sistema de relaciones,

48 Schidlowsky 2011: 167-179 (en alemán e inglés) y Schidlowsky 2012: 179-191 (en español).

49 Ver Dahlhaus 1965: 31-32 y Ligeti 1965: 42-43. 
los cuales se leen proporcionalmente de acuerdo a su tamaño y distribución en el espacio. A esta categoría corresponden, junto a los neumas musicales, también las letras aisladas del alfabeto, los signos de dinámica, etc. Los símbolos en cambio son figuras que no se relacionan directamente con la interpretación musical, sino que proveen información adicional, la que aporta al contexto semántico de la obra. A esta segunda categoría pertenecen los recortes de revistas correspondientes a objetos (objetos de propaganda, rostros, etc.), los cuales sólo pueden inspirar asociativamente a la interpretación.

En el primer movimiento, Du sollst nicht, se pueden observar claramente ambas categorías. Los neumas musicales se encuentran en su mayoría enmarcados en el rectángulo inferior izquierdo. Las letras y fonemas aislados repartidos en el espacio están destinados al coro, mientras que las frases provenientes de recortes de revistas deben ser declamadas libremente por la cantante y el recitador. Los diversos objetos figurativos provenientes de los recortes no son traducibles en música, sino que buscan transmitir un contexto semántico a los ejecutantes.

En otro plano se encuentran los componentes eminentemente performativos, los cuales no suelen ser parte de la notación musical tradicional. Básicamente se trata de las instrucciones de movimiento que hacen de cada gráfica una especie de mapa. Esto se aplica tanto al coro como a los solistas. Tal como en DADAYAmasONG, el movimiento en escena está aquí relacionado con la distribución de los signos en el espacio. Los cantantes pueden elegir libremente en la partitura los fonemas para cantar, junto con ocupar en el escenario el lugar correspondiente al que ocupan ellos en la partitura. Se ha señalado que en la mayoría de las siete partes de esta obra el orden de los fenómenos musicales es libre. No obstante, en el quinto movimiento la cantante solista deberá seguir los números de la cosmología, los que puede repetir a voluntad. En este movimiento se puede observar a su vez cómo el color no sólo transmite asociativamente una atmósfera musical, la cual deberá ser recreada libremente por el pianista y la percusión, sino que debe ser entendido a su vez como una instrucción de iluminación para la escena. El color cumple este rol en todos los demás movimientos (ver imagen 7).

Considerando que la idea del creador es proyectar las gráficas durante la interpretación, se puede afirmar que todos los elementos del teatro musical han sido determinados por el compositor: la música, el texto, la escenografía, la iluminación y el movimiento en escena. León Schidlowsky no es el primer compositor en integrar instrucciones coreográficas en su notación musical. No obstante, será difícil encontrar obras de otros compositores que integren no sólo el movimiento, sino que también la iluminación y la escenografía tan coherentemente en la notación musical, la cual se transforma de este modo en una representación de la obra musical como un todo. En este movimiento en particular incluso se encuentran, encerrados en un cuadrado al extremo izquierdo, una pluma roja y hojas verdes, objets trouvés que pueden ser utilizados como accesorios reales por la cantante durante su interpretación. De esta manera, los diversos medios se encuentran al interior del collage, reunidos en una "atmósfera" particular en la cual no es posible separar los elementos musicales de los visuales, la cual recuerda al concepto de Kandinsky de la obra como un "organismo viviente". En su interior, la atmósfera obedece a 


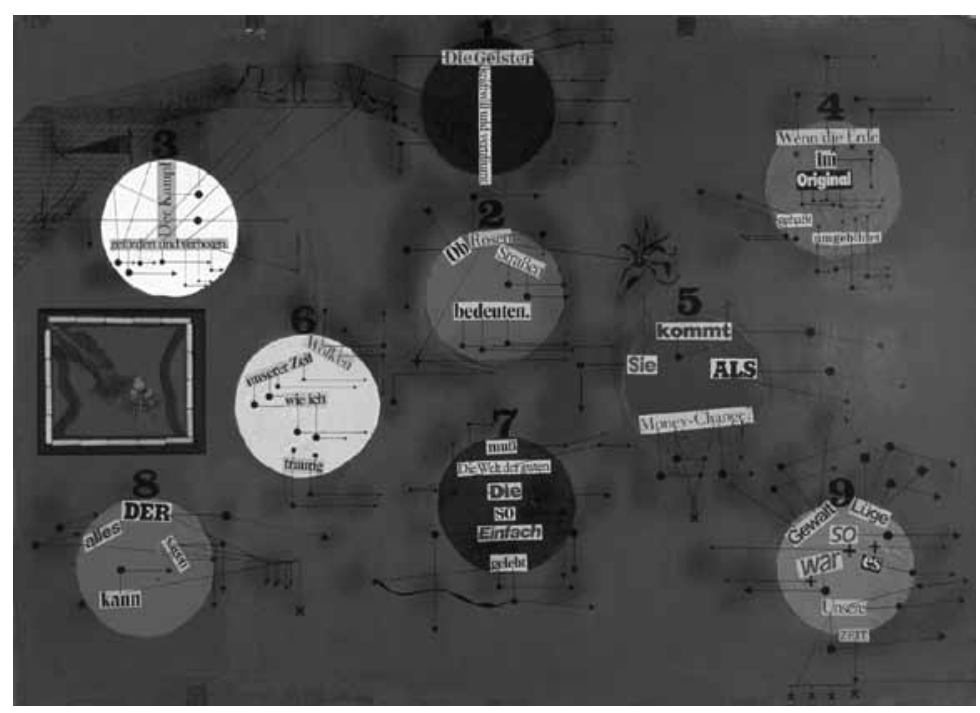

Imagen 7. Deutschland, ein Wintermärchen, quinto movimiento: Weltanschauung. León Schidlowsky, archivo personal.

una concepción sonora específica, determinada en este caso por los efectos que el compositor exige de la parte vocal e instrumental. La cantante deberá interpretar el texto de acuerdo a los neumas que proveen a cada sílaba de una técnica vocal, una dinámica y una altura altamente diferenciada, mientras que los instrumentistas pueden guiarse asociativamente por los elementos visuales proporcionados. Por otra parte, dicha atmósfera está dada por el color real proyectado en el escenario, por el movimiento de la cantante claramente delimitado por sus gestos en relación con el texto a interpretar y por los requisitos de que se le ha provisto. La atmósfera obedece a una concepción sonora específica determinada por diversos efectos, estructuras musicales y timbres, pero también por una concepción visual proporcionada por el color real, el movimiento, los gestos de los cantantes, etc.

El concepto de Gesamtkunstwerk es generalmente conocido a través de la recepción de la obra de Richard Wagner. Sin embargo, no fue este compositor el primero, ni tampoco el último, en valerse de una concepción sintética de las $\operatorname{artes}^{50}$. La peculiar idea de Gesamtkunstwerk utilizada por Schidlowsky tampoco se asemeja en su estética a la de Wagner. Más bien hace recordar nuevamente a algunas obras de los expresionistas, como fueran el drama musical Die glückliche Hand (1913) de Arnold Schönberg o la composición escénica Der gelbe Klang (1912) de Kandinsky. Estas son obras continuadoras de la idea de la Gesamtkunstwerk, en las que sus autores propusieron una novedosa síntesis de

50 Para mayores informaciones sobre la génesis y desarrollo del concepto de Gesamtkunstwerk, véase Borchmeyer 1995. 
color, movimiento y música, dentro de la cual estos tres elementos tendrían igual importancia y alcanzarían un grado de abstracción hasta entonces desconocido. Como señalara el compositor:

"Es cierto que quise sintetizar la música, la literatura, el color [...], el teatro, el movimiento. Ya no quería yo que la música se fuera produciendo nada más que desde un determinado lugar, sino que se fuera moviendo, desplazando, pero no con el fin dramático de las óperas de Wagner, a pesar que hay drama también en la cosa que hago; hay drama, hay lirismo, hay de todo. [...] Es una obra de arte completa, es cierto. Pero no es un Gesamtkunstwerk basado en el Leitmotiv de Wagner, no hay un Leitmotiv aquí, todo lo contrario, la idea es no tener un Leitmotiv" 51 .

En la aplicación de la técnica del collage se encuentra también la influencia de otras tendencias artísticas del mismo período, especialmente del dadaísmo. Sus exponentes apelaban a una renovación radical de los medios artísticos y a la abolición de los cánones y convenciones al interior de la sociedad. Para ello integraron elementos de la publicidad y de la prensa escrita en sus obras gráficas y experimentaron con diversas formas de representación escénica. El lenguaje lo redujeron a su sonoridad, libre de contenidos, trabajando con fonemas y ruidos y reemplazando a los instrumentos musicales por objetos diversos ${ }^{52}$. Muy especialmente se puede nombrar aquí también a Kurt Schwitters (1887-1948), creador de su propio movimiento Merz. Él postuló en sus collages una libertad absoluta para la creación artística y un valor igual para todos los materiales imaginables reunidos en su interior. Mientras que la actitud de los dadaístas era eminentemente rupturista, Schwitters apelaba todavía a la fuerza de la obra artística y a su poder de alcanzar a cualquier ser humano maduro, más allá de diferencias sociales y políticas ${ }^{53}$.

Si bien la concepción de collage multimedial de Schidlowsky va más allá de los ejemplos anteriores, al romper de manera radical con las concepciones de la notación musical tradicional y atravesar además las barreras entre las distintas artes, se encuentra en él, tal como en Schwitters, a un artista que sigue creyendo en la obra de arte y en su capacidad de impresionar al ser humano, como se verá más adelante. En suma, desde el punto de vista estético Schidlowsky parece alcanzar, con esta peculiar concepción, la utopía de una notación que refleje de una sola vez a una obra artística que deviene en el tiempo. En sus propias palabras:

"La música gráfica se presenta como una totalidad espacial, una visualización completa de un arte que es temporal y no fácilmente exequible. Por esta razón su carácter temporal se transforma en una espacialidad finita. En otras palabras, en la visión de un segundo puedo tener la imagen plástica del aspecto total de una obra espacial"54.

\footnotetext{
${ }^{51}$ Entrevista de León Schidlowsky con la autora, 7 de septiembre de 2011.

52 Widmaier 1995.

53 Schmalenbach 1984.

54 Schidlowsky 1979: 1, texto inédito.
} 
De esta manera, la notación alcanza una cualidad propia de las artes plásticas al permitir recorrer con la vista el mensaje musical en todos sus aspectos performativos, relacionándose con la percepción del espacio, del movimiento, de la luz, de lo dramático, junto con constituir una especie de "fotografía instantánea" utópica, una visualización simultánea de un arte temporal. Más allá del aspecto sonoro propiamente tal, el lector podrá hacerse una idea del movimiento, de la luz y del dramatismo de la obra, transmitido plásticamente por la notación.

\subsection{Música y compromiso}

"Junto a la necesidad especulativa de los objetos musicales en sí mismos, cada obra mía es un reportaje de la vida, donde mi compromiso humano, político y social está ligado a la música que escribo" 55 .

Según ya se indicó, la atrevida concepción estética de esta obra no podría entenderse en su significado profundo si no se la interpreta como portadora de un mensaje que apela directamente al ser humano. A lo largo de toda la obra, sus textos e imágenes comunican mensajes que critican directamente a la sociedad que surge con posterioridad a la Segunda Guerra Mundial, y más específicamente a la alemana. Se confrontan imágenes y frases actuales, combinadas indistintamente, en una mezcla versátil, muchas veces irónica. Por una parte se encuentran alusiones a la sociedad de consumo, en frases como "de corazón, su nuevo automóvil” y "para grandes y para chicos, entre a ver" (cuarto movimiento), o "con el oro, nadie ha perdido dinero" y "sus dioses son los autos de sus sueños" (sexto movimiento), acompañadas de imágenes de relojes, joyas, labios pintados, sonrisas, etc. Por otra parte se observan textos referentes a los problemas y amenazas de la actualidad, tales como "pan para el mundo" y "ayuda para vivir" (primer movimiento), o "energía atómica", "suicidio", "tiemblo" y "última advertencia" en el tercer movimiento. En su atmósfera verdosa el tercer movimiento parece buscar la transmisión de un clima de amenaza que es muy diferente a la atmósfera irónica, por ejemplo, del segundo y del cuarto movimiento.

El quinto movimiento constituye un momento especial dentro de la obra. Al contrario de los demás, la gráfica no contiene imágenes de revistas. Su construcción figurativa alude a planetas sobre un espacio azul que corresponde al título de "cosmovisión", lo que da pie para interpretar el poema enmarcado en los distintos círculos como una cosmogonía personal del compositor. Mientras el orden de las palabras dentro de cada círculo puede ser elegido a voluntad, las frases poseen un contenido que no se altera mayormente con el cambio de su orden interno. Este número, para solista, es de un carácter más introspectivo. Aparentemente busca transmitir los pensamientos del compositor lejos de toda ironía cuando dice: "la lucha, promovida y prohibida" o "nubes de nuestro tiempo, como yo tristes". Concluye con un mensaje de denuncia: "violencia, mentira, así fue nuestro tiempo".

55 Schidlowsky 1979: 2, texto inédito. 
Otras frases de la obra aluden directamente a la guerra, como "crímenes de guerra", "no olvidar" (sexto movimiento). Así se prepara el contenido del final de la obra, El sueño del Cuarto Reich, el cual reúne las alusiones anteriores en una gráfica cuyo contenido, como también su aspecto visual y su sonoridad son fuertes y directos. Sus frases transmiten un mensaje claro, sin lugar a dobles interpretaciones: "En el nombre del pueblo alemán / Fuera con el pueblo / En Alemania no hay pobres / Judíos, fuera!” El collage, de colores sucios en los que predominan el rojo y el negro, alude claramente a la figura de la estrella de David, desfigurada, contorsionada y rodeada de letras y fonemas que sugieren, en conjunto, la palabra "fascismo" (F-a-sch-i-s-m-u-s). De acuerdo a las instrucciones del compositor, la última frase, "Juden raus!", puede repetirse cuantas veces se quiera (ver imagen 8).

La fuerza de las palabras, declamadas por el recitador y el coro, junto a las imágenes de guerra, sangre y svásticas del collage, se refuerza por redobles de tambores, indicados en la partitura en los extremos superiores, inferiores y laterales. Mientras que en los movimientos anteriores se hablaba de una gran libertad para la parte instrumental, aquí los tambores se encuentran estrictamente organizados. Asimismo, el movimiento prescinde de los neumas vocales altamente diferenciados presentes en otros movimientos. La escritura de la percusión obedece a una compleja estructura simétrica, como se puede observar en el siguiente esquema (ver imagen 9).

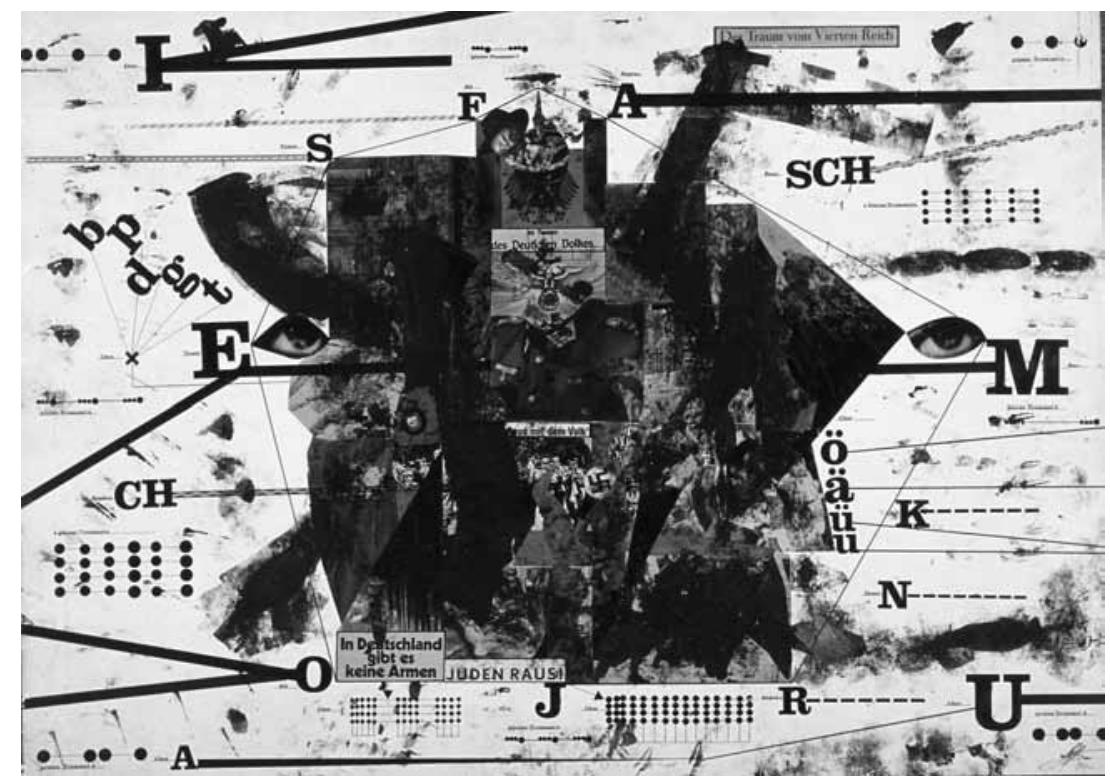

Imagen 8. Deutschland, ein Wintermärchen, séptimo movimiento: Der Traum vom Vierten Reich. León Schidlowsky, archivo personal. 


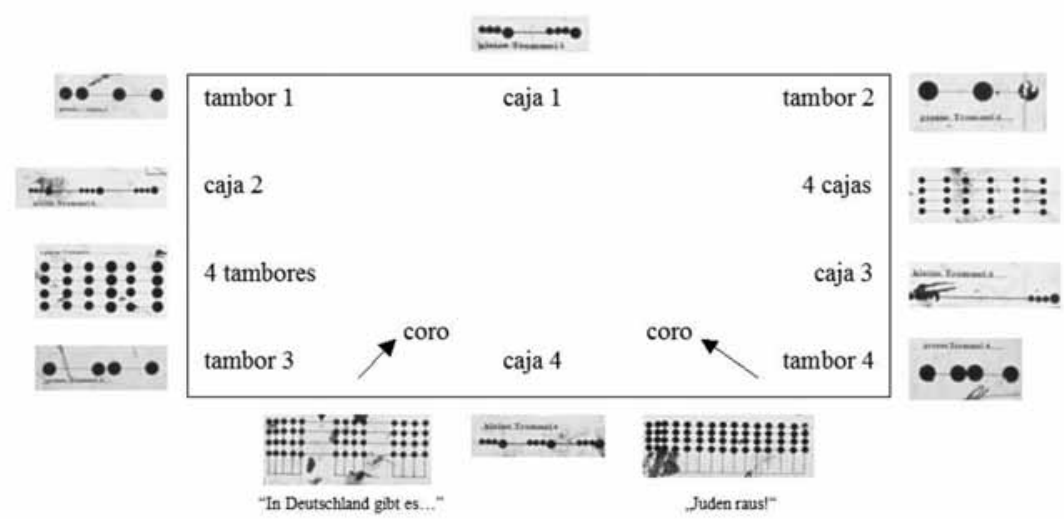

Imagen 9. Deutschland, ein Wintermärchen, séptimo movimiento: esquema rítmico.

La escritura rítmica de los tambores consiste en un sistema proporcional, mientras que el tamaño de las figuras alude a la dinámica. Esta forma de notación recuerda a obras de los años 60, en las que Schidlowsky experimentó con una "problemática polirrítmica abstracta" 56 . El autor se refiere a la percusión de este movimiento como a un ostinato en forma de marcha, el que puede ser interrumpido a voluntad. ${ }^{57}$ No obstante, de la diversidad de las figuras rítmicas señaladas se desprende que el compositor no piensa en una marcha en el sentido tradicional del término, sino en un bloque de percusión altamente diferenciado. Dentro de este bloque el término "marcha" contribuye en primera línea a destacar su carácter bélico, consecuente con la visualidad de la gráfica. Si bien un análisis detallado de esta estructura sobrepasaría los límites de este artículo, es importante recalcar nuevamente la existencia de complejas estructuras tras la aparente libertad de la notación. En su entrevista con la autora, el compositor afirmó que "no existe arte sin estructura" y se refirió a la importancia que, en su caso, juega la numerología, específicamente la cábala judía, como base en la estructuración de sus obras ${ }^{58}$. Este importante aspecto de la obra del compositor no ha sido todavía abordado por la investigación musicológica.

Como se puede observar en este movimiento, el contenido político y social de su mensaje es transmitido de manera directa, sin matices ni metáforas. La fuerza de la imagen visual del texto, de la música, se verán aumentadas por el movimiento y la gestualidad de los intérpretes, que comunican el mensaje crítico sin reservas.

En síntesis, la ya señalada ruptura de las convenciones de la notación musical y la atrevida multimedialidad de la obra guardan relación con la fuerza del mensaje político, expresado abiertamente a través de imágenes y textos directos en su contenido y complementado por la fuerza de los aspectos visuales y musicales

\footnotetext{
56 Ver Grebe 1968: 40-42.

57 Véase el texto del catálogo en Schidlowsky 2011: 178.

58 Entrevista de León Schidlowsky con la autora, 7 de septiembre de 2011.
} 
del movimiento. Así, el revolucionario concepto estético no puede ser visto sino en relación con el subversivo mensaje político, que busca generar reflexión en el receptor. El aspecto político parece haber conquistado el plano de la notación musical, dentro de una forma que se adecue a su esencia.

Pero reducir a Schidlowsky, en su aspecto crítico, al tema de su identificación con el pueblo judío y el holocausto, sería un error. Al contrario, en esta obra, tal como en otras, el compositor se manifiesta comprometido con temas que son comunes a la humanidad más allá de sus diferencias culturales. Como señalara Habakuk Traber:

"Querer rastrear en su obra el límite en que termina la influencia del holocausto y su preocupación por la mística judía y su historia, o en que comienza su reacción a los conflictos actuales de la humanidad, me parecería un sinsentido que desvirtuaría la intención de su creación" $"$.

En algunos ejemplos posteriores a 1969 es posible encontrar un mensaje relacionado directamente con Chile, como es el caso de la gráfica Chile (1976), la cual forma parte de su Misa sine nomine. Esta gráfica, compuesta para 20 cantantes acompañados de instrumentos percutidos, testimonia la postura del compositor frente a los acontecimientos chilenos a partir del golpe militar de 1973. La fuerza de su imagen se incrementa por la presencia de un documento real, una fotografía de una persona golpeada por personal de las fuerzas armadas durante una protesta. Esta imagen corresponde a un símbolo, un elemento semántico inmerso en la gráfica. Difícilmente se podrán encontrar ejemplos similares de citas del mundo real, tales como críticas políticas directas, integradas coherentemente dentro de la notación musical. La concepción hace recordar al Luigi Nono de Non consumiamo Marx (1968/69), obra electrónica (segunda parte de Musica-manifesto Nr. 1) en la que el compositor integra grabaciones de las protestas de estudiantes, trabajadores e intelectuales contra la Biennale de Venecia en 1968 junto a textos tomados de murales del París del 68. Pero se podría decir que Schidlowsky va más allá en su integración, al pasar la cita del plano sonoro al plano visual (ver imagen 10).

León Schidlowsky se siente de hecho cercano a Nono, otro compositor comprometido con los problemas de la sociedad de su tiempo, cuando dice:

"Tomo el camino que eligiera Luigi Nono. Primero hay que escuchar algo internamente para luego poder traducirlo en signos. Esto se podría designar como mi expresionismo: un lenguaje de signos que refleja a la realidad tal como yo me adentro en ella a través de mi propia visión. [...] La música es política, es compromiso con la vida de los seres humanos. Ella está creada y ocupada por hombres. Su objetivo es alcanzar a otros seres humanos. Creo que el arte es un camino hacia nosotros mismos. Al crear he aprendido a expresar el mundo dentro de mí, sin miedo y sin transar en compromisos" 60 .

59 Traber 2004: 216.

60 Schidlowsky, citado por Fresis 9/2001: 31. 


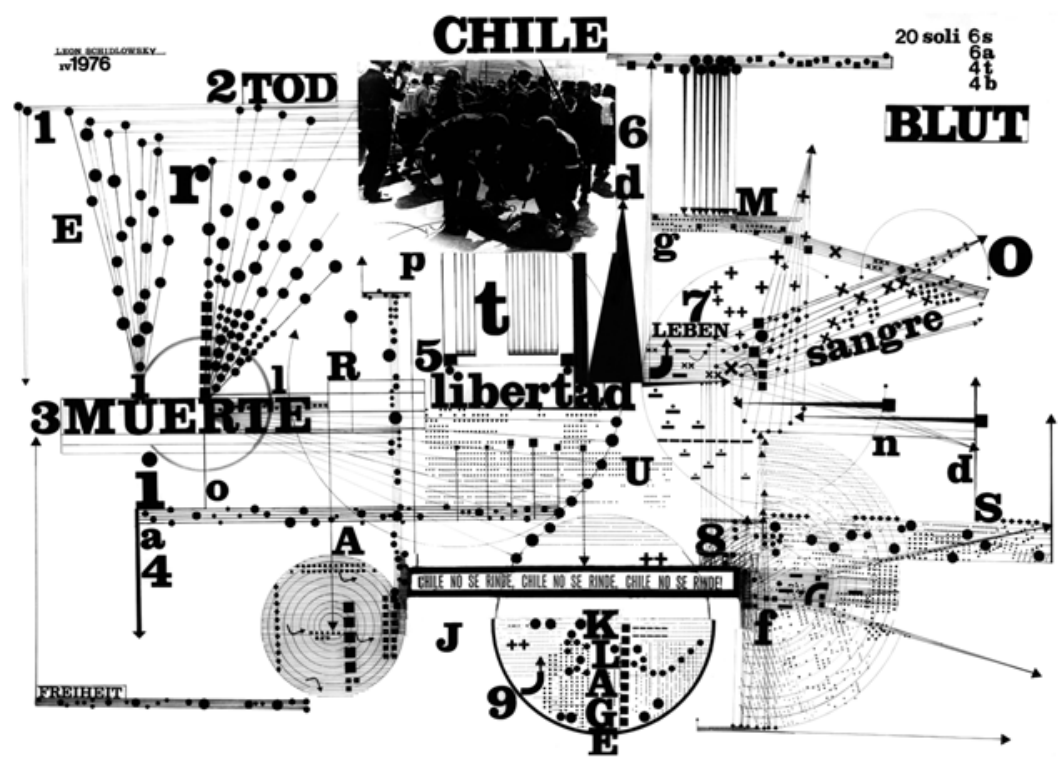

Imagen 10. Misa sine nomine (1976/77), quinto movimiento: Chile (1976).

León Schidlowsky, archivo personal.

\section{CONCLUSIONES}

A lo largo de este estudio se ha buscado demostrar cómo León Schidlowsky ha desarrollado un lenguaje musical gráfico que desemboca en una concepción peculiar del teatro musical integrado, el que se entiende como un "collage multimedial”. Al pasar el elemento dramático a ocupar un papel cada vez más central, el compositor se transforma en el creador de una Gesamtkunstwerk, como dramaturgo, escenógrafo, iluminador, etc. En la síntesis coherente de todos estos elementos al interior de la notación musical, la gráfica transmite una particular cualidad del acto de la lectura, que permite recorrer con la vista un arte temporal, en una visualización simultánea. En tal sentido, es importante destacar que el concepto, pese a su multimedialidad, es prioritariamente musical. Se trata de la representación gráfica de una realidad musical, con todo lo que ella involucra, ya que la música jamás ha existido solamente en la partitura o en terminos de su calidad sonora. Tampoco puede ser disociada de sus aspectos performativos, tales como movimiento, gestualidad, interacción entre los intérpretes, ritualidad, etc.

Entre las posibles influencias estéticas de esta concepción se han nombrado exclusivamente artistas residentes en Alemania o Austria, dentro del período que se inicia a partir de 1910. Sin embargo, la concepción multimedial de Schidlowsky se presta para incluir elementos provenientes de culturas, estilos y lenguajes disímiles, los que se integran en el marco de una concepción artística coherente. De esta manera, la concepción no es sólo multimedial, sino que puede ser a su vez multilingüística y multicultural, junto con sobrepasar barreras culturales, estilísticas, 
etc. Su Wintermärchen contiene en sí una línea intelectual germana espiritual y comprometida que se extiende desde Heine hasta el expresionismo, la que a su vez es testimonio de la historia judía del siglo XX. Pero su mensaje se irradia, más allá de estas influencias, al ser humano en los tiempos de la sociedad de consumo, que se adentra en los años 80 , independientemente de su lugar de procedencia.

$\mathrm{Al}$ comienzo de este estudio se planteó la pregunta por la esencia de la obra de compositores eminentemente transculturales. Al respecto, se podría señalar que esta concepción presenta justamente una solución en la que hay cabida para las influencias más diversas. Tal vez sea este tipo de concepto heterogéneo más natural para un migrante, un compositor que no escribe desde la periferia, sino que simplemente no se adhiere a la creencia en centros canónicos. Esto le permite trabajar libremente con los elementos que le interesan, creando una estética individual y multifacética.

Para finalizar, se ha observado que la idea de collage al interior de la obra no es meramente paródica, ya que el compositor todavía cree en la capacidad del arte de apelar al ser humano, de hacerlo reflexionar y tal vez de cambiar el mundo. En sus palabras:

"Busco una armonía que no es muy agradable, jse los advierto! [...] Busco otra cosa, busco hacerlos despertar, hacerlos tener una postura con respecto a lo que sucede en el mundo. Nosotros tenemos la responsabilidad de cambiar el mundo. La filosofía ha intentado interpretar el mundo, pero nosotros tenemos que transformarlo"61.

\section{BIBLIOGRAFÍA}

Escritos no publicados

Obras GRÁficas de León SchidlowsKy

1972 Música para piano y vientos, de Tetrálogo. Archivo personal del compositor.

$1975 D A D A Y A m a s O N G$. Israel Music Institute (IMI).

1976 Chile. Israel Music Institute (IMI).

1979 Deutschland, ein Wintermärchen. Archivo personal del compositor.

\section{Grabaciones de obras de León Schidlowsky}

1998 Misa sine nomine. Grabación del 12 de septiembre de 1998. CD 4012831190436. Dirección de Ingo Schulz. Berlín: Musik art.

2000 Greise sind die Sterne geworden, eine moderne Passion. Grabación del 25 de martzo de 2000. CD 4012831190634. Dirección de Ingo Schulz. Berlín: Musik art.

2005 León Schidlowsky zum 75. Geburtstag. Werke von 1952 bis 2005. Grabaciones de septiembre de 2006. CD 4260031182342. Dirección de Ingo Schulz. Berlín: Musik art.

61 Palabras introductorias al concierto de su obra Greise sind die Sterne geworden, originariamente en alemán. Grabación en CD, Berlín, 25.3.2000. 


\section{Obras de otros compositores}

1968/69 Luigi Nono. Musica-manifesto Nr. 1, parte 2: Non consumiamo Marx. Grabación. Archivo Luigi Nono, CD 347.

\section{Escritos no publicados}

Herrera Ortega, Silvia

1985 El serialismo-dodecafónico en Chile. Tesis para optar al grado de Licenciado en Musicología. Santiago: Universidad de Chile, Facultad de Artes.

SCHIDLOWSKY, LEÓN

1979 "Música con notación gráfica”, 2 pp., con un comentario adicional escrito el año 2010. Archivo personal del compositor.

2010 Misa sine nomine, 6 pp. Archivo personal del compositor.

[sin fecha] Deutschland, ein Wintermärchen, 3 pp. Archivo personal del compositor.

Bibliografía de artículos y libros

ANÓNIMO

1968 Primera Muestra del Cine Documental Latinoamericano / Primer Festival Internacional de Música. Mérida, 21-30 de septiembre de 1968. Archivo Luigi Nono.

Autores VARIOS

1997 "Los años cincuenta en Chile: una retrospectiva”, RMCh, LI/187 (enero-junio), pp. $42-62$.

BORCHMEYER, DiETER

1995 "Gesamtkunstwerk", Die Musik in Geschichte und Gegenwart. Editada por Ludwig Finscher. Sachteil. Tomo III. Kassel e.a.: Bärenreiter, col. 1282-1289.

Claro, Samuel

1963 "Panorama de la música experimental en Chile”, RMCh, XVII/83 (enero-marzo), pp. 111-118.

Dahlhaus, Carl

1965 “Notenschrift heute”, Notation Neuer Musik [Darmstädter Beiträge zur Neuen Musik, tomo 9]. Mainz: B. Schott's Söhne, pp. 9-34.

Fresis, ERRICo

2001 "Zwischen Bergen und Meer. Der chilenische Komponist León Schidlowsky", Neue Musikzeitung, volumen 7-8, p. 35, y Neue Musikzeitung, volumen 9, p. 31.

González, Juan Pablo

2006 "Música: de la partitura al disco", en 100 años de cultura chilena, 1905-2005. Editado por Juan Andrés Piña y Daniella Gutiérrez. Santiago de Chile: Zig-Zag, pp. 201-252.

Grebe, María Ester

1968 “León Schidlowsky Gaete. Síntesis de su trayectoria creativa (1952-1968)”, RMCh, XXII/104-105 (abril-diciembre), pp. 7-52.

Heine, Heinrich

2005 Deutschland, ein Wintermärchen [1844]. Hamburgo: Insel. 
KANDINSKY, WASSILY

1955 Punkt und Linie zur Fläche [1926]. Tercera edición. Editado por Max Bill. BernaBümpliz: Benteli.

KARKOSCHKA, ERHARD

1966 Das Schriftbild der Neuen Musik. Winterthur y Zürich: Hermann Moeck.

1979 “Zu 'Musikalischer Graphik' und León Schidlowsky’s einschlägigen Arbeiten”, León Schidlowsky. Musikalische Graphik. Catálogo de la exposición, Stuttgart, 16 de noviembre al 17 de diciembre. Stuttgart: Staatsgalerie Stuttgart, pp. 11-13.

1980 "León Schidlowsky’s 'DADAYAmasONG'. Eine musikalische Graphik und ihre Interpretation", Notenschrift und Aufführung. Simposio de la Gesellschaft für Musikforschung 1977. Editado por Theodor Göllner. Tutzing: Hans Schneider, pp. 137-147.

LIGETI, GYÖRGY

1965 "Neue Notation - Kommunikationsmittel oder Selbstzweck?”, Notation Neuer Musik [Darmstädter Beiträge zur Neuen Musik, tomo 9]. Mainz: B. Schott's Söhne, pp. 35-50.

Möller, Harmut E.A.

1997 "Notation", Die Musik in Geschichte und Gegenwart. Editada por Ludwig Finscher. Sachteil. Tomo VII. Kassel e.a.: Bärenreiter, col. 275-432, especialmente parte "VIII. 20. Jahrhundert", por Rudolf Stephan, col. 350-355.

Merino Montero, Luis

2003 “1973-2003: treinta años”, RMCh, LVII/199 (enero-junio), pp. 39-56.

SCHIDLOWSKY, LEÓN

1966 "In Memoriam Hermann Scherchen", RMCh, XX/97 (julio-septiembre), pp. 109-110.

1979 León Schidlowsky. Musikalische Graphik. Catálogo de la exposición, Stuttgart, 16 de noviembre al 17 de diciembre. Stuttgart: Staatsgalerie Stuttgart.

1982 León Schidlowsky. Musikalische Graphik. Catálogo de la exposición, Ludwigshafen, 24 de abril al 31 de mayo.

2011 León Schidlowsky. Musikalische Graphik - Graphic Music. Editado por David Schidlowsky. Berlín: Wissenschaftlicher Verlag (WVB).

2012 León Schidlowsky. Gráfica musical. Editado por David Schidlowsky. Santiago de Chile: RIL editores.

Traber, Habakuk

2004 "Holocaust-Kompositionen in Israel. Identitätsstiftung und Ritualisierung", Jüdische Musik? Fremdbilder - Eigenbilder. Editado por John Eckhard y Heidy Zimmermann. Colonia: Böhlau, pp. 195-217.

VON MAUR, KARIN

1979 "Notizen zum Thema Musik - Malerei - Musikalische Graphik", León Schidlowsky. Musikalische Graphik. Catálogo de la exposición Stuttgart, 16 de noviembre al 17 de diciembre. Stuttgart: Staatsgalerie Stuttgart, c5-10.

1985 Vom Klang der Bilder. Die Musik in der Kunst des 20. Jahrhunderts. Catálogo de la exposición, Stuttgart, 6 de junio al 22 de septiembre. Munich: Prestel. 


\section{WidMAIER, TOBIAS}

1995 "Dadaismus", Die Musik in Geschichte und Gegenwart 2. Editada por Ludwig Finscher. Sachteil (tomo) II. Kassel e.a.: Bärenreiter, col. 1053-1057.

\section{Páginas Web}

http://schidlowsky.com/Leon-Schidlowsky.htm

http://www.gfm-dhi-rom2010.de

\section{Entrevistas}

Entrevista de la autora con Ingo Schulz, Berlín, 10 de marzo de 2011.

Entrevista de la autora con León Schidlowsky, Berlín, 7 de septiembre de 2011. 